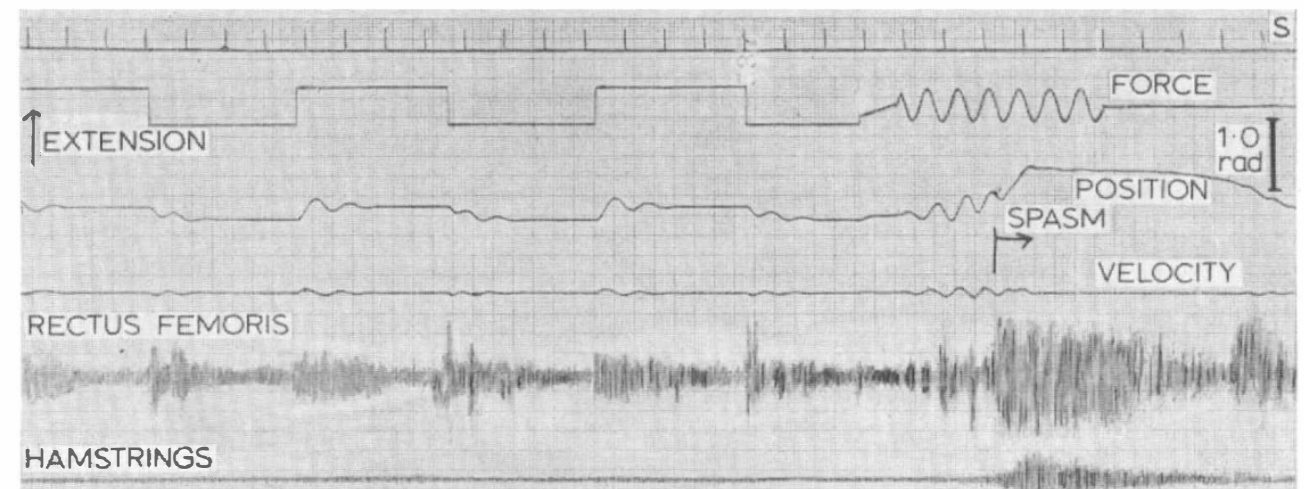

VASTUS MEDIALIS

FIG. 2

Polygraph during simultaneous electrical and mechanical recording.

Financial support for these studies has been provided by Roche Products Ltd., and by a Government Grant from the Royal Society.

\title{
HOSPITAL ACTIVITY ANALYSIS
}

\author{
By Dr. J. B. Cook, M.D., F.R.C.P. \\ Consultant Neurologist, Pinderfields General Hospital, Wakefield
}

\section{Abstract}

IN December 1968, an investigation was made into the admission of traumatic paraplegia and tetraplegia to a spinal injuries unit, using a computer under the scheme of Hospital Activity Analysis.

On checking the information provided by the computer with the notes of the patients known to have been discharged from the unit, it was found that the diagnostic information from the computer was grossly inaccurate, covering a wide field of diagnosis from epilepsy to tonsillectomy.

On comparing the computer estimate of readmissions during one year, the computer was found to be 26 per cent. in error, and in comparing the discharges of new patients during one year, the computer error was 38 per cent.

It was considered that although the difficulties of diagnostic coding are very great, the clinician must attempt to achieve accuracy.

It is thought probable that the figures provided by Hospital Activity Analysis are not sufficiently reliable to be used for purposes of planning. 